\title{
Immigration and school composition in Ireland
}

\author{
Delma Byrne*, Frances McGinnity, Emer Smyth and Merike Darmody
}

\section{The Economic and Social Research Institute, Dublin, Ireland}

\begin{abstract}
In the last decade, Ireland has experienced a rapid increase in immigration on a scale previously unknown in the country's history. Over this time, Ireland has been transformed to an increasingly heterogeneous country in terms of nationality, language, ethnicity and religious affiliation. These changes have also impacted on the composition of Irish schools. The article draws on data collected for a large-scale study of primary and second level school provision for immigrant students. The findings indicate the absence of the degree of school segregation found in many European countries, mainly due to the geographical dispersal of the immigrant population and the wide variety of national groups represented. However, the interaction between geographical location, parental choice of schools and school admissions criteria means that immigrant students are overrepresented in larger schools, schools located in urban areas and those with a socio-economically disadvantaged intake.
\end{abstract}

Keywords: school composition; segregation; immigrant students; Ireland

\section{Introduction}

Ever since James Coleman's 1966 study of Inequality of educational opportunity which pointed to the existence of substantial racial segregation in American schools, the concentration of social and ethnic groups and their segregation relative to other groups have been studied in immigrant-receiving countries. While the concentration of racial and ethnic groups in schools has been found to differ across institutional contexts, the concerns driving these studies remain uniform across systems: inequality of educational achievement, a concentration of poverty, social isolation in certain neighbourhoods, and segregation (Clotfelter 2001). Within this context, the issue of the distribution of immigrant ${ }^{1}$ students across Irish schools is of particular interest. After decades of net emigration from Ireland, the strong economic growth of the last decade and resulting rapid immigration of non-Irish nationals has transformed Ireland into a country of net immigration. As a result, Irish society has become more diverse in terms of nationality, language, ethnicity and religious affiliation. Approximately $10 \%$ of the national population are immigrants, and immigrant children are now reflected in the composition of the student body at both primary and second level education.

Previous Irish research has highlighted the experiences of immigrant students during the initial phase of immigration (see, for example, Devine, Kenny, and McNeela 2002) as well as the experiences of specific immigrant groups, such as unaccompanied minors (see Ward 2004). Variation has also been found in the school

*Corresponding author. Email: Delma.Byrne@esri.ie 
experiences of different national or ethnic groups (see Devine 2005; Nowlan 2008). However, because of a lack of national data, very little is currently known at the national level about how immigrant students are distributed across Irish schools, and whether schools which have immigrant students differ from those who have not. It is important to know about the distribution of immigrant children across Irish schools because of the potential effects of ethnic and socio-economic school segregation. This paper addresses this gap in knowledge by drawing on data from the first largescale national research study conducted on immigrant students in Irish primary and second level schools (Smyth et al. 2009). The main research questions being addressed in this paper are:

- What is the distribution of immigrant students across primary and second level schools? A clustering of immigrant students in specific schools may have implications both for social integration and for school provision.

- What is the distribution of immigrant students by nationality/national profile? To what extent are national groups segregated or mixed in schools? Is there evidence that certain nationalities/national groups are dominant in particular schools?

- Do some schools have a high proportion of immigrant students relative to other schools? If so, does the share of immigrant students in a school differ according to various school-level characteristics such as disadvantaged status and geographic location? Are such patterns in Ireland consistent with international findings?

The remainder of the paper is outlined as follows. In the next section, we outline the way in which a rapid influx of immigrant children of a diverse group of relatively highly-educated, mostly non-English speaking migrants into a previously (almost) culturally/ethnically monolithic school population occurred. This section is followed by an overview of the Irish education system. We then use the international research on immigrant students in schools to explain why segregation may occur and to derive hypotheses to guide the analyses. The data, variables and method are then outlined before presenting the results in two stages. Finally, we conclude with a summary of findings and a discussion of the composition of Irish schools in the wake of rapid immigration.

\section{Immigration in the Republic of Ireland}

There are a number of aspects of immigration that are specific to the Irish context. Many European countries have a long history of immigration. In contrast, immigration to Ireland has taken place in the last decade only and at a speed unprecedented in comparative context as a result of the emergence of widespread labour shortages between 1993 and 2004. In recent years, migratory flows to Ireland have become less dominated by return Irish migration (who made up $50 \%$ of immigrants in 1996 compared to less than 25\% in 2006) and much more dominated by the migration of other nationality groups to Ireland (CSO 2008). Over this short period of time, Ireland has been transformed to a heterogeneous population as the share of immigrants increased from 3\% in 1993 (Sexton 2003) to $6 \%$ in 2002 to $10 \%$ in 2006 (CSO 2008). 
Second, unlike other European countries, migration patterns to Ireland are diverse in terms of the national groups concerned. Historically, other countries have experienced migration flows from specific countries (e.g., Turks in Germany) resulting in relatively large numbers of particular minority ethnic groups. Immigration to Ireland is characterised by its diversity of nationalities, a pattern which is likely to reduce the capacity of immigrant communities to build up extended social networks upon arrival. Table 1 presents information on the national composition of the Irish population in 2002 and 2006 (see CSO 2008). In 2006, just over 10\% of the population were foreign nationals who can be typically divided into four groups. The largest non-Irish group, UK nationals, have been resident here for longer than the other groups, with significant numbers having been in Ireland since the 1970s and 1980s, though the majority migrated in the 1990s. EU15 nationals (excluding UK and Ireland) represent people from the 15 states comprising the EU before 2004, namely: Austria, Belgium, Denmark, Finland, France, Germany, Greece, Italy, Luxembourg, Netherlands, Spain, Sweden and Portugal. A majority of this group arrived in the period 2001-2006, though many also migrated in the 1990s. The third group is EU16 to EU25 Accession State nationals, that is, nationals of: Cyprus, Czech Republic, Estonia, Hungary, Latvia, Lithuania, Malta, Poland, Slovakia and Slovenia. This group saw the largest growth between 2002 and 2006, reflecting the accession of these states to the EU in 2004. The 'Rest of the world' category is a diverse group of non-EU nationals; in Table 1 they are further broken down into 'Other European', 'US', 'African', 'Asian' and 'Other' nationalities. Table 1 shows that of all non-Irish nationals, two-thirds were nationals of other EU countries (including the UK), and one third came from outside the EU25. This compares to

Table 1. Total population in 2002 and 2006 classified by nationality

\begin{tabular}{|c|c|c|c|c|}
\hline Nationality & 2002 & $\%$ & 2006 & $\%$ \\
\hline Irish & $3,584,975$ & 92.9 & $3,706,683$ & 88.8 \\
\hline \multicolumn{5}{|l|}{ Non-Irish EU nationals } \\
\hline UK & 103,476 & 2.7 & 112,548 & 2.7 \\
\hline Other EU15 & 29,960 & 0.8 & 42,693 & 1.0 \\
\hline EU16 to EU25 Accession States & - & - & 120,534 & 2.9 \\
\hline Total EU & 133,436 & 3.5 & 275,775 & 6.6 \\
\hline \multicolumn{5}{|l|}{ Rest of the world (non-EU) } \\
\hline Other European & 23,105 & 0.6 & 24,425 & 0.6 \\
\hline USA & 11,384 & 0.3 & 12,475 & 0.3 \\
\hline Africa & 20,981 & 0.5 & 35,326 & 0.8 \\
\hline Asia & 21,779 & 0.6 & 46,952 & 1.1 \\
\hline Other nationalities & 11,236 & 0.3 & 22,422 & 0.5 \\
\hline Multi/no nationality & 3187 & 0.1 & 3676 & 0.1 \\
\hline Not stated & 48,412 & 1.3 & 44,279 & 1.1 \\
\hline Total non-Irish* & 224,261 & 5.8 & 419,733 & 10.1 \\
\hline Total population & $3,858,495$ & 100.0 & $4,172,013$ & 100.0 \\
\hline
\end{tabular}

Note: *Excludes 'no nationality' and 'not stated'. The Census counts 'persons usually resident and present in the State on census night'. Some commentators believe the non-Irish population may be underestimated, even by the Census.

Source: Central Statistics Office (2008). 
patterns in 2002 when $60 \%$ came from other EU countries and $40 \%$ from outside the EU15 (CSO 2008).

Third, the educational profile of immigrants to Ireland is quite distinctive. Research on the Irish labour market has shown considerable evidence of overqualification among non-English speaking immigrants (Barrett, Bergin, and Duffy 2006). Many are highly educated but not working in jobs commensurate with their skills, suggesting that individuals who have decided to settle in Ireland are a selfselect high-skilled group (see Chiswick 1999, 2000). However, despite high education levels, language has emerged as a key issue in terms of labour market integration, with migrants from non-English-speaking countries experiencing higher levels of labour market disadvantage than migrants from English-speaking countries (Barrett and McCarthy 2007; O'Connell and McGinnity 2008). A further barrier to labour market integration is racism and research on the experience of racism has found that black South/Central Africans in Ireland are much more likely to experience racism than white East Europeans, with Asians in a more intermediate position (McGinnity et al. 2006). Whilst the parents of immigrant children may experience considerable labour market disadvantage, it is likely that their higher education levels will result in higher educational expectations for their children.

Finally, while much of the European and American research indicates that immigrants tend to be concentrated in cities or large metropolitan areas (see Borjas 2000; Cebolla-Boado 2007; Fejaer and Birkelund 2007; Gronqvist 2006; Rangvid 2007), the Census of Population revealed that in April 2006 there were non-Irish nationals living in every town in Ireland, with the majority of immigrants living in the cities and large towns. The main factors influencing the spatial distribution of labour immigrants in Ireland are the location of jobs, and the price/affordability of housing. Each of these factors will be important when explaining the distribution of migrant children in Irish schools and will be discussed in more depth in the paper.

\section{The Irish education system}

Ireland represents a very interesting case study for analysing the distribution of immigrant students across schools both at primary and second level, given the structure of the Irish education system in terms of religious affiliation, social composition and geographic spread. Primary schools in Ireland are predominantly denominational, mainly Catholic in nature, with a small proportion of multidenominational schools. While primary schools are found in both urban and rural areas, a significant number of primary schools are located in rural areas. Second level schools comprise three sectors: voluntary secondary schools (mainly founded by religious orders), vocational and community/comprehensive schools. They fall within a common curriculum and assessment framework but differ in their management and funding structure. In addition, they have been found to differ in their student intake, with more middle class and higher 'ability' students over-represented in voluntary secondary schools (Hannan et al. 1996). Just $8 \%$ of second level schools charge fees to their students, and just $8 \%$ of both primary and post-primary schools are Irish-medium schools (DES 2009). Under the DEIS (Delivering Equality of Opportunity in Schools) programme, ${ }^{2}$ additional funding is allocated to schools which have a greater concentration of students from more disadvantaged backgrounds. The differences between DEIS and non-DEIS schools can be quite stark 
and imply an increasing ghettoisation of those schools designated as disadvantaged (Smyth and McCoy 2009). Because of existing social disparities in processes of school choice, we expect that existing lines of inequality are likely to affect the distribution of immigrant students across schools. This point will be further developed in the paper.

\section{International research on migrant children in schools}

International research points to demographic trends and residential segregation, school characteristics, parental choice of schools and school admission policies as factors that contribute to the placement of immigrant children in schools (CebollaBoado 2007; Fejaer and Birkelund 2007; Gronqvist 2006; Karsten et al. 2003; Kristen 2008; OECD 2006; Rangvid 2007). This paper draws on the international empirical literature which largely focuses on the concentration of ethnic groups (rather than immigrant status) in schools. Given that studies on immigration in Ireland are in their infancy, this literature will be used to guide the analyses and derive hypotheses about the concentration/distribution of immigrant students across Irish schools.

\section{Demographic trends and residential segregation}

In the international literature, the spatial dynamics of ethnic groups have been instrumental in explaining educational segregation (Cebolla-Boado 2007; Fejaer and Birkelund 2007; Gronqvist 2006; OECD 2006; Rangvid 2007). In many European cities, there is empirical evidence of segregation by ethnic origin, and schools with high concentrations of ethnic minority pupils are mainly found in the cities. In a number of European countries that have experienced an increased inflow of immigrant children, evidence suggests that the new arrivals tend to concentrate in certain geographic areas. In Norway, Fejaer and Birkelund (2007) note that immigrant pupils often settle in disadvantaged areas and are often segregated residentially, particularly in areas with a high population. In Sweden, Gronqvist (2006) observes that immigrants tend to settle in residential areas that are predominantly inhabited by other immigrants. In Denmark, Rangvid (2007) found that immigrant students tend to be concentrated in big cities. In many cases, immigrant and/or ethnic groups tend to be clustered in specific schools. An OECD study found that more than $30 \%$ of first generation immigrant students attend schools where at least half of the student population has an immigrant background (OECD 2006). ${ }^{3}$ Cebolla-Boado (2007) in France finds that the concentration of immigrant students in schools follows a non-random pattern and concludes that these patterns result from prior sorting mechanisms that distribute students across school divisions.

As in other European countries, the majority of the immigrant population (particularly those from EU15 countries and the rest of the world) in Ireland is found in cities but the Irish pattern deviates somewhat, with a high distribution of the immigrant population also found in large towns (CSO 2008). Of the major cities, Dublin and Cork have the highest share of immigrants and a high proportion of immigrants are also found in popular tourist destinations on the western and southern seaboards. Given the growth of the service and the construction industries 
during the boom, immigrants are also found in small and medium sized towns as well as rural areas. However, UK nationals are more likely to be found in rural areas than other immigrants. Furthermore, with the exception of UK nationals, non-Irish nationals are much more likely to live in rented accommodation (CSO 2008). Rented accommodation is associated with particular problems of affordability, and it is likely the high cost of housing has a strong impact on the spatial distribution of immigrants (CSO 2008). While little is known about the residential segregation of immigrants and ethnic minorities in cities, it is likely that most of the minority populations are found in certain areas of Dublin. However, much less is known about the voluntary concentration of population groups. Given that the majority of the immigrant population in Ireland is found in cities and large towns, we expect that the share of immigrant students in both primary and second level schools is likely to be greater in schools in urban rather than rural areas.

\section{School characteristics}

Much of the international literature focuses on the characteristics of schools when considering the distribution/concentration of immigrant students or ethnic groups (Kristen 2008; OECD 2006). This research has considered the extent to which immigrant students attend schools with a high proportion of students whose families have also immigrated. In several countries, many immigrant students attend schools with high proportions of first generation or second generation students (OECD 2006). International research has also highlighted patterns in the characteristics of schools that immigrant students attend relative to native students (OECD 2006). Immigrant students have been found to be more likely to attend schools with a socioeconomically disadvantaged intake and, in some cases, poorer learning conditions (OECD 2006). In several European countries, the school environment for immigrant students compared to native students is less favourable in terms of the school or disciplinary climate (see for example Kristen 2008). In Germany, Kristen (2008) found some evidence that Turkish students are more likely to attend common district schools that accommodate more immigrant students and which are associated with lower academic achievement than Catholic elementary schools. Whilst the study of the distribution of immigrant students across schools is in its infancy in the Irish context, Irish studies have pointed to clear social differentiation in terms of the type of school that native Irish students attend. Secondary schools tend to have a more middle-class profile than either vocational schools or community/comprehensive schools and are more likely to be oversubscribed (Breen 1986; Hannan et al. 1996; Smyth 1999).

Based on these findings, we expect a number of patterns to be evident. First, because of existing social differentiation at second level, we expect that immigrant students will be more likely to attend vocational or community/comprehensive schools than secondary schools. Second, it is likely that fees will be a deterrent to parents of immigrant students because of the costs involved in moving to another country. Thus, we expect that immigrant students will be less likely to attend feepaying schools than native students. Third, we expect that immigrant students will be more likely to attend DEIS rather than non-DEIS schools, at least in part because 
DEIS schools are less likely to be oversubscribed than non-DEIS schools. We also expect that there will be differences in composition between urban and rural schools because the majority of the immigrant population in Ireland is found in cities and large towns.

\section{Socially and ethnically motivated parental choice and school admissions policies}

Building on the previous section, parental choice has been found to play a role in the concentration of immigrant groups in certain schools. In an analysis of all Dutch elementary schools, Karsten et al. (2003) found that the ethnic composition of a school is a factor in parental choice, although with ethnic and Dutch parents giving different reasons for their choice of school. For native Dutch parents, the match between home and school ('people like us') was the most important factor while for ethnic parents, the degree of differentiation (attention given to difficulties in learning Dutch) and the academic standard of the school were the most important factors. Furthermore, Karsten et al. (2003) found that differences were evident according to levels of education among parents, with parents who had lower levels of education indicating that distance to school was the most important motive for school choice. When asked about schools that they had not chosen, non-white schools in a neighbourhood were often judged 'unsuitable' by native Dutch parents and by ethnic minority parents, while the white schools in a locality were most often judged to be suitable by both (Karsten et al. 2003).

Another important reason for studying the Irish situation is the long-standing tradition of free school choice. Unlike in other educational systems, in Ireland there is no requirement that young people attend their local school. As a result of this freedom, it is estimated that half of parents choose second level schools that are their own preference (Byrne and Smyth in press; Hannan et al. 1996). ${ }^{4}$ Parental choice in determining what school their child attends may however be constrained by economic, geographic or religious circumstances. In this regard, more middle-class parents are likely to make active school choices by locating themselves near particular schools or sending their children to schools that match their religious or other beliefs and/or socio-economic intake. Thus, parents who have 'insider' knowledge of the educational system are more likely to successfully negotiate access to their preferred school. In contrast, the recent arrival of immigrant parents means that they will be 'outsiders' in terms of knowing how the school system operates.

While parental choice plays a role in the distribution of immigrant students across schools, international evidence also suggests that school segregation of immigrant students can be a result of school admissions policies. The nature of student intake to a particular school will be influenced by the extent to which different groups of parents choose that school for their children. Where schools are oversubscribed (that is, have more applicants than places), they employ a range of admissions criteria, including date of application, having older siblings in the school and (in the case of second level schools) the primary school attended (see Smyth et al. 2009). Certain admissions criteria, such as waiting lists and having had older children attend the same school, are likely to impinge on immigrant families in particular, thus restricting their 'choice' to undersubscribed schools. 


\section{Data, variables and method}

The data used in this paper are derived from the first national study on provision for the needs of immigrant students in Irish primary and second level schools. It builds upon previous research to combine national survey data with in-depth case studies from both school sectors. ${ }^{5}$ The data derive from a postal survey of all second level principals (733) and a sample of 1200 primary principals selected to be representative of all primary schools in size, location and disadvantaged (DEIS) status. The second level survey was sent out in March 2007 while the primary survey was sent out in September $2007 .{ }^{6}$ A high response rate was achieved from both primary and second level schools (62\% and 63\% respectively). The data were reweighted to ensure they are fully representative of the national population of schools. For further details of the survey and a copy of the questionnaire see Smyth et al. (2009).

The analyses are presented in two stages in this article. First, descriptive results are presented outlining the percentage of immigrant students as a share of the total population of primary and second level schools, the distribution of immigrant students across Irish schools and the nationality of immigrant students in Irish schools. Second, multivariate analyses are conducted to consider the distribution of immigrant students across schools according to a number of school characteristics. The dependent variable used is the proportion of immigrant students in a school as reported by the principal in the survey, and the school is the unit of analysis resulting in 735 primary schools and 448 second level schools. We estimated Tobit regression models for the share of immigrant students in a school as a function of the following school characteristics; denominational status of the school, geographic location (urban/rural), DEIS status, language of the school (Gaelscoil ${ }^{7} v$. English-medium $^{2}$ school), school size, school sector (for second level schools), and fee-paying status. Traditional ordinary least squares (OLS) regression techniques assume that the dependent variable is normally distributed. However, this is not the case with the distribution of immigrant students since a significant number of schools have no immigrant students at all. Instead, we use a Tobit regression model which explicitly takes account of such a situation. The Tobit model will be discussed in more depth when the analyses are presented.

\section{Results: descriptive overview}

\section{Prevalence}

Table 2 shows that out of a total primary school population of 476,600 in September 2007, there were 45,700 immigrant students, making up around $10 \%$ of the total primary school population. At primary level, over three quarters of immigrant students were non-English speaking. We estimate that in a second level total school population of around 327,000, there were approximately 18,000 immigrant students; thus immigrant students made up $6 \%$ of the total second level population in Spring 2007. Furthermore, $70 \%$ of these immigrant students were non-English speaking. 
Table 2. Descriptive overview of immigrant and native students in Irish schools

\begin{tabular}{lccc}
\hline & $\begin{array}{c}\text { Total student } \\
\text { population }\end{array}$ & $\begin{array}{c}\text { Total immigrant } \\
\text { student population }\end{array}$ & $\begin{array}{c}\text { Immigrant students as a } \\
\text { share of the total population }\end{array}$ \\
\hline Primary & 476,000 & 45,700 & $10 \%$ \\
Second level & 327,000 & 18,000 & $6 \%$ \\
\hline
\end{tabular}

\section{Distribution}

While it is important to know about the share of immigrant students in the school population as a whole, further insights can be gleaned by looking at the proportion of immigrant students in individual schools. Figure 1 shows the proportion of immigrant students as a proportion of the population across primary and second level schools.

There are a number of marked differences between the primary and second level sectors in Ireland regarding the distribution of immigrant students. First, while $90 \%$ of second level schools record immigrant students in their student body; this is the case for just $56 \%$ of primary schools. Second, most second level immigrant students are in schools with a low proportion of immigrant students; in almost half of second level schools immigrants make up between $2 \%$ and $9 \%$ of the student body, In contrast, primary schools tend to have higher proportions of immigrant students or none at all; $44 \%$ of primary schools have no immigrant students while almost 1 in 10 primary schools has over $20 \%$ immigrant students. In sum, the level of clustering of immigrant students is somewhat more pronounced in primary schools than in second level schools.

A further approach was taken to consider the extent to which immigrants are concentrated in certain schools (analyses not shown here). That is, we consider what percentage of immigrant students in Ireland are in schools where there is a high proportion of immigrant students and what percentage of them are in schools where there is a low proportion. We find that most second level immigrant students in Ireland are in schools with a relatively low proportion of immigrant students. However, almost half of immigrant students attending primary schools are in

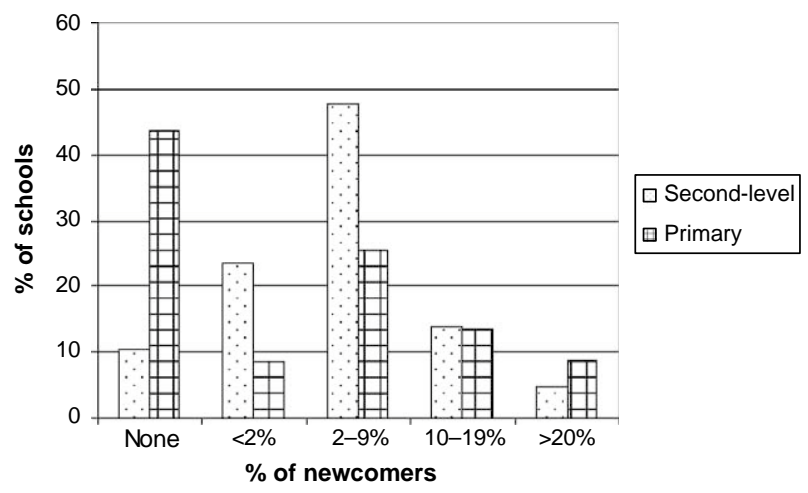

Figure 1. Irish schools, showing the proportion of immigrant students (school-level) 
schools where immigrants make up more than $20 \%$ of the student population (see Smyth et al. 2009).

\section{Nationalities of immigrant students}

The nationality of immigrant students in a school is important in a number of respects. The nationality of a student is usually a good indicator of English language competency, which may have a crucial impact on learning outcomes. Nationality may also indicate cultural distance, where certain nationalities may be seen as 'further' from Ireland than others, in terms of customs, cultural reference points, religion and a shared identity (or lack of it). Equally, the mix of nationalities in a school may have a profound effect on how immigrant students settle in, integrate and develop, both socially and academically. If an immigrant child is surrounded by co-nationals who speak their native language at school, this may be a rather different experience from attending a school where nobody speaks their language. This child may settle in initially, though their social and linguistic integration may be delayed. Similarly, if the school wants to translate some school information, this is a different task if there are two languages in the school rather than 30.

Detailed nationality information was not recorded in our survey, but the postprimary school database from the Department of Education and Science records students of around 160 nationalities attending second level schools in the school year 2006-2007, reflecting the substantial diversity of the student intake in Irish schools. From our study it was possible to classify the country of origin of immigrant students according to the following eight national groups:

- UK nationals.

- Other EU15 (excluding Britain and Ireland).

- EU10 (Accession State nationals).

- Non-EU Eastern European nationals.

- Nationals of USA, Canada, New Zealand and Australia.

- Latin American nationals.

- Asian nationals.

- African nationals. ${ }^{8}$

Figure 2 indicates that schools with immigrant students have a range of different national groups in their student body, particularly at second level. National groups are not quite so mixed at primary level, though there too, three quarters of schools with immigrant students have two or more groups. Having more national mixing at second level suggests that there may be a certain amount of local residential segregation which influences primary school intakes, but this gets 'diluted' at second level, where schools have larger catchment areas. These figures are consistent with recent migration patterns outlined in Table 1.

While the overall picture is of a substantial mix of nationalities in most Irish schools, some national groups are more prevalent in schools than others when we consider the proportion of schools with any immigrant students from a particular national group. While not shown here, at second level, $85 \%$ of schools with immigrant students have students from the EU10 Accession States (including Romania and Bulgaria), reflecting the recent rapid increase in the number of East 


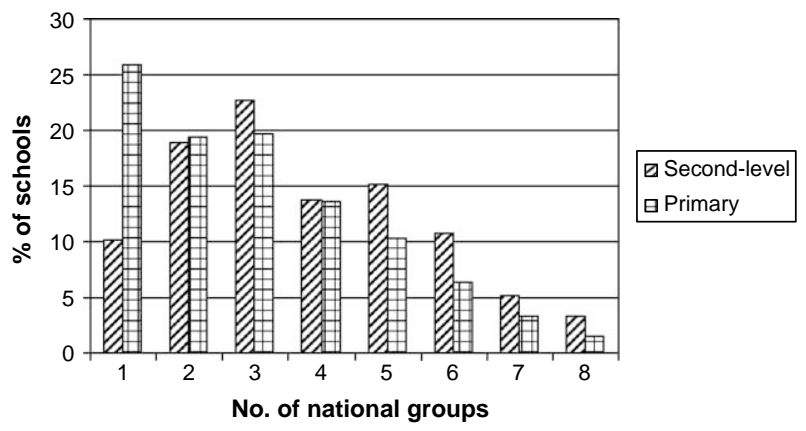

Figure 2. Number of national groups in schools with immigrants in their student body

European nationals in Ireland. Fifty-eight per cent of second level schools have Asian nationals and 55\% have African nationals. Unsurprisingly, half of schools with immigrant students have UK nationals (51\%). ${ }^{9}$ At primary level, $79 \%$ of schools have EU10 Accession State nationals, 53\% have Asian nationals and 54\% have African nationals. While this measure records any immigrant students from these countries, it is important to note that in some cases the numbers concerned could be very small, as low as one student.

With such a mix of nationalities, it is not possible to characterise schools as 'Asian' or 'East European' in profile. The closest we can get to the national 'character' of the immigrant student body is to consider what proportion of schools have one 'dominant' national group. When we consider the figures for primary and second level schools for the national groups most prevalent in Irish schools (analyses not shown here), it becomes clear that East European nationals are mostly likely to be the dominant group - in one third of second level schools and $40 \%$ of primary schools. In $61 \%$ of second level schools and almost 80 per cent of primary schools, Africans, Asians or West Europeans make up over half of the immigrant student body. However, it should be stressed that these national groups are highly heterogeneous, not least in the range of languages spoken. In sum, descriptive analyses indicate no empirical evidence of segregation by nationality in Irish schools; in fact, as illustrated by Figure 2, there is a variety of nationalities in many schools with immigrant students.

\section{Results: multivariate analyses}

We now consider the school-level characteristics that are associated with the student body in relation to the share of immigrant students in a school. Do schools that have immigrant students differ significantly from those who do not? Are there certain types of schools in Ireland which do not have immigrant students? What are the school characteristics associated with having immigrant students in the student body? In this section, we explore the simultaneous effect of a number of school characteristics on the proportion of immigrant students in schools. This is not necessarily straightforward. Ordinary least squares (OLS) regression assumes a continuous distribution of the dependent variable or outcome. We know from the descriptive analysis that this assumption cannot be made in this instance since a significant number of primary and second level schools have no immigrant students 
at all. Thus, if we use OLS regression techniques, the result will be biased estimates (Breen 1996). Logistic regression modelling could be used to assess the impact of school characteristics on whether a school has any immigrant students. However, this means that we are 'throwing away' detailed information on the proportion of immigrant students in a school. A Tobit model overcomes these difficulties by taking account of whether a school has any immigrant students and of the representation of immigrants in the relevant school. This type of modelling has been used extensively in research on school effectiveness (see, for example, Coleman, Hoffer, and Kilgore 1982).

Table 3 presents the results of a Tobit model used to assess the factors influencing the distribution of immigrant students across primary schools. The sample comprises 734 schools of which $56 \%$ had immigrant students. Positive coefficients indicate that certain factors are associated with a greater representation of immigrant students while negative coefficients show that these factors are associated with a lower representation of immigrant students. The findings indicate that five school-level variables are significantly associated with the share of immigrant students in a school. Thus, all else being equal, there are lower proportions of immigrant students in Catholic than in non-Catholic (minority faith or Educate Together) schools. ${ }^{10}$ Immigrants are also less highly represented in Gaelscoileanna than in Englishmedium schools. Higher proportions of immigrant students are found in urban schools and larger schools. As predicted, immigrant students are more highly

Table 3. Factors influencing the percentage of immigrant students in Irish primary schools (Tobit regression model)

\begin{tabular}{lrcc}
\hline & Coefficient & Standard error & Significance level \\
\hline Constant & 1.247 & 2.180 & 0.567 \\
Catholic & -6.370 & 2.257 & 0.005 \\
Ref: Other & & & \\
Urban & 5.693 & 1.826 & 0.002 \\
Ref: Rural & & & \\
DEIS rural & -0.291 & 2.767 & 0.916 \\
Ref: Non-DEIS rural & 10.380 & 2.161 & 0.000 \\
DEIS urban & & & 0.000 \\
Ref: Non-DEIS urban & -10.413 & 2.866 & 0.000 \\
Gaelscoil & & & 0.000 \\
Ref: English-medium school & 6.176 & 1.698 & 0.000 \\
100-199 students & 12.595 & 1.850 & \\
200-399 students & 16.719 & 2.792 & \\
400+ students & & & \\
Ref: $<100$ students & 16.32 & 0.57 & \\
Sigma & & & \\
Pseudo R ${ }^{2}=.15$ & & & \\
N $=734$ & & & \\
\hline
\end{tabular}

Source: Survey of principals, primary schools. 
represented in designated disadvantaged (DEIS) schools, but this effect is confined to urban areas.

There is less variation in second level schools, as $90 \%$ of second level schools have immigrant students. Table 4 outlines the school-level factors influencing the distribution of immigrant students across Irish second level schools. Just three of our school-level characteristics are significantly associated with the share of immigrant students in second level schools. In relation to second level schools, we find that there are higher proportions of immigrant students in urban schools and in designated disadvantaged (DEIS) schools. As at primary level, we find lower proportions of immigrant students in Gaelcholáistí than in English medium schools. Contrary to our hypothesis, no significant difference is found in the representation of immigrants in fee-paying schools. This may reflect the fact that a number of fee-paying schools cater to boarders, who may come from outside Ireland but are not permanent residents.

The other findings are largely in line with our original hypotheses. The greater representation of immigrant students in urban schools reflects residential patterns whereby the immigrant population is more concentrated in cities and larger towns. Immigrants are more likely to attend designated disadvantaged (DEIS) schools, which reflects the greater ease of accessing undersubscribed schools which are located in urban areas. Immigrant students are underrepresented in Gaelscoileanna and Gaelcholáistí, a pattern which is likely to reflect the reluctance of non-Englishspeaking immigrant families to learn an additional new language. In sum, the representation of immigrant students across schools must be seen in the context of

Table 4. Factors influencing the percentage of immigrant students in Irish second-level schools (Tobit regression model)

\begin{tabular}{lrcc}
\hline & Coefficient & Standard error & Significance level \\
\hline Constant & 3.904 & 1.364 & 0.004 \\
Boys' secondary school & -0.971 & 1.090 & 0.373 \\
Coed secondary school & 0.892 & 1.061 & 0.401 \\
Vocational school & -0.250 & 1.110 & 0.822 \\
Community/comprehensive & 0.749 & 1.261 & 0.553 \\
Ref: Girls' secondary school & & & 0.009 \\
Urban & 2.160 & 0.824 & 0.002 \\
Ref: Rural & & & \\
DEIS & 2.993 & 0.943 & 0.106 \\
Ref: Non-DEIS & 2.180 & 1.348 & 0.000 \\
Fee-paying & & & \\
Ref: Non fee-paying & -6.269 & 1.483 & 0.467 \\
Gaelcholáiste & & & 0.687 \\
Ref: English-medium school & 0.850 & 1.167 & 0.883 \\
Up to 399 students & -0.492 & 1.218 & \\
Between 400 and 599 students & 0.195 & 1.321 & \\
600+ students & & & \\
Ref: Less than 399 students & 6.978 & 0.250 & \\
Sigma & & & \\
Pseudo R ${ }^{2}=.18$ & & &
\end{tabular}


wider demographic trends, residential patterns, parental choice of schools and school admissions policies.

\section{Discussion and conclusion}

Economic growth and labour shortages as well as the opening up of Europe have resulted in Ireland experiencing significant recent migration and significant change in the student composition of Irish schools. This paper has emphasised the importance of considering the distribution of immigrant students across Irish schools given that education is central to processes of reproduction in society and the school is a crucial site for the integration of immigrant children, young people and their parents into Irish society. In doing so, it has provided the first systematic picture of how immigrants navigate the Irish school system and the implications for their distribution across schools. Specifically, we set out to examine the composition of Irish schools after a period of rapid immigration in relation to:

- the distribution of immigrant students across primary and second level schools;

- the extent to which national groups are segregated or mixed in Irish schools; and

- whether some schools have a high proportion of immigrant students relative to other schools; and if so, whether the share of immigrant students in a school differs according to school-level characteristics.

Results from this national study indicate that the distributions are rather different at primary and second level. At second level, the vast majority of schools (around $90 \%$ ) have immigrant students, but many second level schools have a rather small proportion of immigrant students, between $2 \%$ and $9 \%$. At primary level, over $40 \%$ of schools have no immigrant students, but those who do tend to have a greater proportion of immigrant students.

The finding of different patterns at primary and second level is consistent with how the two sectors operate and interact in the Irish education system. Primary schools tend to draw students from their local area, while second level schools have a much larger catchment area. Typically a number of primary schools feed into any given second level school, so even if one feeder primary school had no immigrants, the second level school in the area would record immigrants if there were immigrant students in other primary schools in the area.

Ireland's experience of immigration is distinctive in terms of its changing nature both in terms of the scale and speed of incoming migration and the shift from return migration to the migration of other nationality groups to Ireland. The diversity of the immigrant groups that have come to Ireland in terms of nationality is reflected in the student body at both primary and second level. This study shows that national groups are particularly mixed at second level but less so (relatively) at primary level. The representation of East European nationals is greater than that from other national groups but, in general, there is a substantial mix of nationalities within individual schools. Having more national mixing at second level suggests that there may be a certain amount of local residential segregation which influences primary school intakes, but gets 'diluted' at second level, where schools have larger catchment 
areas. This finding suggests an absence of school segregation on the basis of nationality which is positive given the international findings in relation to social integration and nationality (Laosa 2001; Logan, Oakley, and Stowell 2002). The patterns of national groups in Irish schools contrast significantly with other European countries, many of which have a few dominant nationalities and which often result in the segregation of particular national groups in certain schools. This is particularly so where there is a long history of migration and established second generation minority groups.

The multivariate analysis of the distribution of immigrant students across Irish primary and second level schools indicates significant variation on the basis of school location (urban/rural), disadvantaged status and language medium. While our study provides little evidence of segregation in the Irish context, in line with international studies we have found that schools with a more socio-economically disadvantaged intake tend to have a higher proportion of immigrant students than other schools, and this is true for both (urban) primary and second level schools. This finding raises concern about whether 'choice' is available for immigrant families given that these schools tend to be undersubscribed relative to non-DEIS schools. The availability of places in the school is therefore a crucial issue in influencing the distribution of immigrant students. Qualitative data from our study indicate that many of the enrolment criteria used by schools tend to favour settled communities, particularly where parents are required to sign up long in advance and preference is given to the siblings of those already in the school. Much inward migration into Ireland is relatively recent and recent immigrants tend to be very geographically mobile. Therefore, immigrant children will inevitably end up in schools which are undersubscribed. This will apply in particular to immigrant children who arrive during the course of the school year. Furthermore, it raises concern as to whether certain groups of students, including immigrants, are concentrated in particular school settings.

Our models also indicated the importance of geographic region and residential patterns in the distribution of immigrant students in Irish schools, indicating that urban schools are more likely to have a higher proportion of immigrant students than rural schools. Given that our study relates to schools rather than local areas, we were unable to investigate in depth the issue of the spatial distribution of immigrants in Ireland and how this relates to the distribution of immigrant students across schools. However, our qualitative data did suggest that many principals feel that residence patterns play a strong role in the distribution of immigrant students. This issue merits further research.

In conclusion, it is important to note that diversity in Irish schools is not just a challenge but a positive resource. Economic forecasts predict a fall in immigration and some tendency towards net emigration in the near future. However, families with children may be more likely to remain in Ireland than single workers because of the roots they have established, and the extent of recent inward migration means that some degree of diversity will be part of Irish society for the foreseeable future.

\section{Acknowledgements}

The authors would like to thank the Department of Education and Science who funded the study, Adapting to Diversity, and are grateful for the comments provided by two external referees. 


\section{Notes}

1. The term 'immigrant' is used throughout to describe a heterogeneous group (in terms of nationality, ethnicity, and language skills as well as length of stay, cultural/religious background and legal status) who have migrated to Ireland. This terminology is used by the authors in a non-pejorative sense.

2. Schools are identified for participation in the DEIS programme on the basis of the prevalence of certain household characteristics (such as unemployment and lone parenthood). Criteria are somewhat different for primary and second level schools (see Smyth and McCoy 2009).

3. These findings were reported in Australia, Belgium, Canada, Luxembourg, the Netherlands, Sweden, Hong Kong and Macao (OECD 2006).

4. Unfortunately, no information is currently available on the extent of active school choice at primary level.

5. A mixed methods approach involving qualitative and quantitative methods was used in the study, as this approach was deemed most suitable for the investigation in question. This approach has become well established in social and educational research internationally and is seen as the 'gold standard' in school studies (see Onwuegbuzie and Leech 2004). This paper is based on the survey data used in the study (Smyth et al. 2009).

6. This occurred because two other large-scale surveys of primary schools were being carried out in Spring 2007 and it was felt that this might negatively impact on the response rate.

7. A Gaelscoil (plural: Gaelscoileanna) is a school which teaches through the medium of Irish. The term Gaelcholáistí refers to Irish-speaking second level schools.

8. Note that each of these groups contains a mixture of nationalities.

9. However, compared to the nationality estimates from the Census of Population 2006, this is likely to be an under-estimate of UK nationals. Though principals were asked to include UK nationals in the immigrant body, it is likely that some UK nationals were not included, either because they had one parent who was Irish, or because they are seen as more similar to Irish students, do not require language provision and principals do not 'register' them as immigrants.

10. Given that Catholic schools make up the vast majority of schools at primary level, the majority of immigrants attend Catholic schools. However, their relative representation is greater in non-Catholic schools.

\section{Notes on contributors}

Delma Byrne is a postdoctoral fellow at the ESRI. Her key areas of expertise include the evaluation of interventions within secondary education, the transition from school to work, and issues surrounding higher education and labour market integration.

Frances McGinnity is a senior research officer and joint programme co-coordinator of equality research at the ESRI. Most of her research to date has examined labour market inequality - unemployment, temporary employment, part-time work, gender and racial discrimination. She is also interested in work-life balance, time use and the integration of migrants in Ireland.

Emer Smyth is a research professor and programme coordinator of education research at the ESRI. Her areas of interest include education, school to work transitions, and women's employment. She has a strong interest in comparative research on education and labour market issues. Currently she is a co-coordinator of a study that explores the transmission of religious beliefs and values through the education system and the family across different EU country contexts.

Merike Darmody is a research officer at the ESRI. She mainly works in the area of education but is also interested in broader issues of the relationship between an individual and society. Her more recent work includes a study focusing on the integration of immigrant students in 
Irish primary and secondary schools. She is also involved in a European comparative study on the provision of religious education in a multicultural society.

\section{References}

Barrett, A., A. Bergin, and D. Duffy. 2006. The labour market characteristics and labour market impacts of immigrants in Ireland. The Economic and Social Review 37, no. 1: 1-26.

Barrett, A., and Y. McCarthy. 2007. The earnings of immigrants in Ireland: Results from the 2005 EU survey of income and living conditions, ESRI Working Paper No. 206. Dublin: ESRI.

Borjas, G.J. 2000. Issues in the economics of migration. Chicago: University of Chicago Press.

Breen, R. 1986. Subject availability and student performance in the senior cycle of Irish post primary schools. Dublin: ESRI.

Breen, R. 1996. Regression models: Censored, sample selected or truncated data. Thousand Oaks, CA: Sage.

Byrne, D., and E. Smyth. In press. Parental involvement in post-primary education. Dublin: The Liffey Press in association with the ESRI.

Cebolla-Boado, H. 2007. Immigrant concentration in schools: Peer pressures in place? European Sociological Review 23, no. 3: 341-56.

Central Statistics Office. 2008. Census 2006: Non-Irish nationals living in Ireland. Dublin: Stationery Office.

Chiswick, B.R. 1999. Are immigrants favorably self-selected? The American Economic Review 89, no. 2: 181-5.

Chiswick, B.R. 2000. Are immigrants favorably self-selected? An economic analysis. Bonn: Institute for the Study of Labor (IZA).

Coleman, J. 1966. Equality of educational opportunity. Washington, DC: US Government Printing Office.

Coleman, J.S., T. Hoffer, and S. Kilgore. 1982. High school achievement: Public, Catholic and private schools compared. New York: Basic Books.

Clotfelter, C.T. 2001. Are whites still fleeing? Racial patterns and enrolment shifts in urban public schools, 1987-1996. Journal of Policy Analysis and Management 20, no. 2: 199-221.

Department of Education and Science. Education Statistics Database. Department of Education and Science. http://www.cso.ie/px/des/database/des/des.asp

Devine, D. 2005. Welcome to the Celtic Tiger? Teacher responses to immigration and increasing ethnic diversity in Irish schools. International Studies in Sociology of Education 15, no. 1: 49-69.

Devine, D., M. Kenny, and E. McNeela. 2002. Ethnicity and schooling. A study of ethnic diversity in selected Irish primary and post-primary schools. Report for the Department of Education and Science. Dublin: University College Dublin.

Fejaer, S., and G. Birkelund. 2007. Does the ethnic composition of upper secondary schools influence educational achievement and attainment? A multilevel analysis of the Norwegian case. European Sociological Review 23, no. 3: 309-23.

Gronqvist, H. 2006. Ethnic enclaves and the attainments of immigrant children. European Sociological Review 22, no. 4: 369-82.

Hannan, D.F., E. Smyth, J. McCullagh, R. O’Leary, and D. McMahon. 1996. Coeducation and gender equality: Exam performance, stress and personal development. Dublin: Oak Tree Press.

Karsten, S., G. Ledoux, J. Roeleveld, C. Felix, and D. Elshof. 2003. School choice and ethnic segregation. Educational Policy 17, no. 4: 452-77.

Kristen, C. 2008. Primary school choice and ethnic school segregation in German elementary schools. European Sociological Review 24, no. 4: 495-510.

Laosa, L. 2001. School segregation of children who migrate to the United States from Puerto Rico. Education Policy Analysis Archives 9, no. 1. http://epaa.asu.edu/ojs/article/view/330

Logan, J.R., D. Oakley, and J. Stowell. 2002. Choosing segregation: Racial imbalance in American public schools 1990-2000. New York: Lewis Mumford Centre for Comparative Urban and Regional Research, University at Albany.

McGinnity, F., P.J. O'Connell, E. Quinn, and J. Williams. 2006. Migrants' experience of racism and discrimination in Ireland. Dublin: ESRI. 
Nowlan, E. 2008. Underneath the band-aid: Supporting bilingual students in Irish schools. Irish Educational Studies 27, no. 3: 253-66.

O'Connell, P.J., and F. McGinnity. 2008. Immigrants at work: Ethnicity and nationality in the Irish labour market. Dublin: Equality Authority.

OECD. 2006. Where immigrant students succeed: A comparative review of performance and engagement in PISA 2003. Paris: OECD.

Onwuegbuzie, A.J., and N.L. Leech. 2004. Enhancing the Interpretation of 'significant' findings: The role of mixed methods research. The Qualitative Report 9, no. 4: 770-92.

Rangvid, B.S. 2007. Living and learning separately? Ethnic segregation of school children in Copenhagen. Urban Studies 44, no. 7: 1329-54.

Sexton, J. 2003. Recent changes in migration movements and policies: Ireland. Trends in international migration. Paris: OECD.

Smyth, E. 1999. Do schools differ? Academic and personal development among pupils in the second-level sector. Dublin: Oak Tree Press.

Smyth, E., M. Darmody, F. McGinnity, and D. Byrne. 2009. Adapting to diversity: Irish schools and newcomer students. Dublin: ESRI.

Smyth, E., and S. McCoy. 2009. Investing in education: Combating educational disadvantage. Dublin: ESRI.

Ward, T. 2004. Education and language needs of separated children. Dublin: City of Dublin VEC, County Dublin VEC, Dun Laoghaire VEC. 